\title{
Üst Ekstremite Yaralanması Olan Bireylerde Kol, Omuz ve El Sorunları Anketi (DASH) Ile Lawton Günlük Yaşam Aktiviteleri Anketi Arasındaki İlişkinin İncelenmesi
}

Investigation of the Relation Between Disabilities of the Arm, Shoulder and Hand Questionnaire (DASH) and Lawton Activities of Daily Living Questionnaire in Individuals with Upper Extremity Injury

\section{Özge Buket CESIM (1), Burcu Semin AKEL (2), Çiğdem ÖKSÜZ (2)}

(1) Erg., Hacettepe Üniversitesi, Sağılık Bilimleri Fakültesi, Ergoterapi Bölümü, Araştırma Görevlisi, Ankara

(2) Doç. Dr., Hacettepe Üniversitesi, Sağlık Bilimleri Fakültesi, Ergoterapi Bölümü, Öğretim Üyesi, Ankara

\section{öz}

\begin{abstract}
Amaç: Çalışmamızın amacı üst ekstremite yaralanmalarına sahip bireylerde Kol, Omuz ve El Sorunları anketi (DASH) ve Lawton Günlük Yaşam Aktiviteleri (LGYA) anketi arasındaki ilişkiyi ortaya koymaktır. Gereç ve Yön-

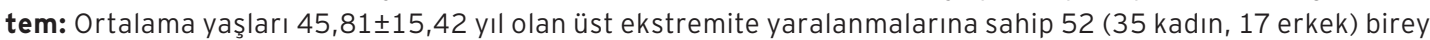
çalışmaya dahil edildi. LGYA anketinin kendine bakım, yemek yeme ve giyinme aktiviteleri değerlendirildi. Bireylere DASH anketinin Türkçe versiyonu (DASH-T) uygulandı. DASH-T ile LGYA anketlerindeki ortak aktiviteleri belirlemek için iki anket içerisindeki maddeler karşılaştırıldı. Sonuçlar: Ortalama DASH-T skoru 38,92 $\pm 25,28$ idi. LGYA kendine bakım ortalaması 25,49, yemek yeme ortalaması 21,92 ve giyinme aktiviteleri ortalaması 26,43 'tü. DASH-T ile LGYA arasında istatistiksel olarak orta düzeyde ilişki bulundu $(r=-0,571, p<0,01)$. DASH-T anketinin, Lawton kendine bakım aktiviteleri $(r=-0,572)$ ve giyinme aktiviteleriyle $(r=-0,579)$ orta düzeyde negatif korelasyona sahip olduğu bulundu $(p<0,01)$. DASH-T' nin, Lawton yemek yeme aktiviteleriyle $(r=-0,394)$ ise düşük-orta düzeyde negatif bir korelasyona sahip olduğu tespit edildi $(p<0,05)$. Tartışma: Çalışmamız sonucunda DASH-T anketinin üst ekstremite yaralanması geçirmiş bireylerin günlük yaşam aktivitelerindeki her parametreyi değerlendirmediği ve LGYA anketinin bu bireylerin aktivite limitasyonlarını belirlemede yetersiz olabileceğini düşünmekteyiz. Bundan dolayı üst ekstremite yaralanması geçirmiş bireylerin günlük yaşamdaki bağımsızlıklarını ayrıntılı olarak değerlendirmek için klinikte DASH-T anketinin yanında özellikle temel GYA' ları değerlendiren ayrıntılı bir GYA değerlendirmesi yapılması önemlidir.
\end{abstract}

Anahtar Kelimeler: DASH; Günlük yaşam aktiviteleri; Üst ekstremite.

Bu çalışma 24-25 Kasım 2016 tarihlerinde, Hacettepe Üniversitesinde 2.Ulusal Sağlık Bilimleri Kongresi'nde poster olarak sunulmuştur. 


\begin{abstract}
Purpose: The aim of our study is to investigate the relation between Disabilities of the Arm, Shoulder and Hand Questionnaire (DASH) and Lawton Activities of Daily Living Questionnaire (LGYA) in individuals with upper extremity injuries. Materials and Methods: Fifty two individuals (35 female, 17 male) with upper extremity injuries and with the mean age of $45,81 \pm 15,42$ years were included. Self-care, eating and dressing activities of LGYA were evaluated. The Turkish version of DASH questionnaire (DASH-T) was also administered. The items in both questionnaire were compared to determine the common activities. Results: Mean score of DASH-T was 38,92 $\pm 25,28$. The mean score of self-care activities of LGYA was 25,49, eating activities of LGYA was 21,92 and dressing activities of LGYA was 26,43 . There was a statistically medium level relationship between DASH-T and LGYA $(r=-0,571, p<0.01)$. Negative medium level correlation was found between DASH-T and Lawton self-care activities $(r=-0,572, p<0,01)$; DASH-T and dressing activities $(r=-0,579, p<0,01)$ and negative low-medium level correlation was found between DASH-T and Lawton eating activities $(r=-0,394, p<0,05)$. Conclusion: As a result of our study we think that the DASH-T questionnaire does not assess every parameter of activities of daily living of individuals with upper extremity injuries and that the LGYA questionnaire may be insufficient to determine the activity limitations of these individuals. Therefore, in addition to DASH-T questionnaire, it is important to perform a detailed ADL assessment in the clinic to evaluate the independence of individuals with upper extremity injuries in daily life, especially those evaluating basic ADLs.
\end{abstract}

Key Words: DASH; Activities of daily living; Upper extremity.

Ü st ekstremite yaralanmaları yumuşak doku yaralanmalarından ampütasyona kadar geniş bir spektrumda ortaya çıkmaktadır (Tuncalı D., 2005). Bu yaralanmalara sahip bireyler ağrı, duyu problemleri, kuvvetsizlik, normal eklem hareketinde kısıtlılık ve fonksiyonel kapasitelerinde azalma gibi problemlerle karşılaşmaktadırlar. Bu problemler sonucu ortaya çıkan bozukluk, aktivite ve katılım kısıtıııklarını değerlendirmeye yönelik klinikte kullanılan birçok değerlendirme mevcuttur. Bunlardan bazıları Michigan El Sonuç Ölçümü, Görsel Analog Skalaları, Sağlık Durumu Anketi Kısa Form (SF-36) ve Kol, Omuz Ve El Sorunları Anketi (DASH) gibi anketlerdir (Davis et al., 1999; Skirven, Osterman, Fedorczyk, \& Amadio, 2011). Literatürde DASH anketi, üst ekstremite yaralanması geçiren bireyleri değerlendirmek için en sık kullanılan ve en güvenilir anketlerden biri olarak belirtilmiştir (Changulani, Okonkwo, Keswani, \& Kalairajah, 2008). Schoneveld, Wittink ve Takken (2009) sistematik derleme çalışmalarında; üst ekstremite yaralanmalarına yönelik bozukluğu değerlendiren birçok standardize ölçümler olmasına rağmen, aktivite ve katılımı değerlendiren ölçümlerin üst ekstremite yaralanması geçirmiş bireylerde geçerlik çalışmaları yapııması gerektiğini ve bu yüzden ileriki çalışmalarda, bu bireylerde günlük yaşam aktivitelerini (GYA) içeren genel değerlendirmelerin hedeflenmesi gerektiğini belirt- mişlerdir (Schoneveld, Wittink, \& Takken, 2009). Benzer olarak, van de Ven-Stevens ve arkadaşları sistematik derleme çalışmalarında el fonksiyon problemi yaşayan bireylerde aktivite ve katılım kısıtlılığını değerlendiren uygun bir ölçüm konusunda fikir birliği olmadığı ve el terapisi alanında günlük yaşam aktiviteleri gibi kişi odaklı değerlendirmelerin henüz yeterince araştırılmadığı sonucuna varmışlardır. Ancak son zamanlarda özellikle günlük yaşam aktivitelerinde bireylerin performansını yansıtan ölçümlere yönelik çalışmaların arttığı belirtilmiştir (van de Ven-Stevens ve diğ., 2009). Üst ekstremite yaralanması geçiren her hasta ve hasta popülasyonunda ayrı ve bireysel olan spesifik faktörleri tanımlamak için daha kapsamlı GYA değerlendirmesine intiyaç duyulduğu açıktır (Skirven, 2011).

Günlük Yaşam Aktiviteleri, hayatta kalmayı ve iyilik halini sağlayan ve sosyal bir dünyada yaşamak için temel oluşturan aktivitelerdir. GYA; temel günlük yaşam aktiviteleri (Temel GYA) ve yardımCı günlük yaşam aktiviteleri (Yardımcı GYA) olmak üzere ikiye ayrılır. Temel GYA; banyo yapma, giyinme gibi bireyin kendi vücudunun bakımına yönelik aktivitelerdir. Yardımcı GYA; genellikle temel GYA' ya göre daha karmaşık etkileşimi gerektiren, ev ve toplum içerisindeki günlük yaşamı destekleyen, ev yönetimi, finansal yönetim gibi aktivitelerdir. ("Occupational Therapy Practice Framework: 
Domain and Process," 2014). Bireylerin günlük yaşam, iş ve serbest zaman aktivitelerini yerine getirmedeki yetenekleri üst ekstremite yaralanmalarından etkilenebilir. Bu yüzden bireylerin aktivite kısıtlılıklarını değerlendirmek önemlidir (van de Ven-Stevens, Munneke, Terwee, Spauwen, \& van der Linde, 2009).

Çalışmamızın amacı üst ekstremite yaralanmalarına sahip bireylerde Kol, Omuz ve El Sorunları (DASH) anketi ile Lawton Günlük Yaşam Aktiviteleri (LGYA) anketi arasındaki ilişkiyi ortaya koymaktır.

\section{GEREÇ VE YÖNTEM}

Çalışmaya Hacettepe Üniversitesi, Sağlık Bilimleri Fakültesi, Ergoterapi Bölümü, Erişkin Ergoterapi Ünitesine başvuran farklı üst ektremite yaralanmalarına sahip 52 birey alındı. Çalışmada Helsinki Deklarasyonu esas alındı. Çalışmaya katılan tüm bireylere Aydınlatılmış Onam Formu imzalatıldı. Çalışmadan hariç tutulma kriteri; bilişsel fonksiyonlarını etkileyebilecek nörolojik veya psikiyatrik hastalık tanısı almış olmak olarak belirlendi.

\section{Kişilerin Değerlendirilmesi}

Bireylerin yaş, cinsiyet, tanı, cerrahi operasyon varlığını içeren sosyodemografik bilgileri alındı. Daha sonra tüm bireylere yazarlar tarafından Kol, Omuz ve El Sorunları (DASH) anketinin Türkçe versiyonu (DASH-T) ve Lawton Günlük Yaşam Aktiviteleri (LGYA) Anketi uygulandı. Bütün değerlendirmeler bireylerin ilk görüşmesinde yapıldı.

\section{Anketlerin Analizi}

Her iki anket içerisindeki aktiviteleri ayrıntılı olarak incelemek ve ortak aktiviteleri belirlemek için DASH-T anketinin günlük yaşam aktivitelerini içeren ilk 21 maddesi ile LGYA anketindeki aktiviteler karşılaştırıldı. Her iki anketteki aktiviteler temel ve yardımcı GYA olarak ayrıldı.

\section{Veri Toplama Araçları}

Kol, Omuz Ve El Sorunları Anketi (Disabilities of the Arm, Shoulder and Hand Questionnaire, DASH), üst ekstremite yaralanmalarında fiziksel fonksiyona odaklanarak fonksiyonel durumu ve semptomları değerlendirmek amacıyla Amerikan Ortopedik Cerrahlar Akademisi tarafından 1994 yılında geliştirilmiştir (Hudak ve diğ., 1996). Anketin birçok ülkede uyarlamasının geçerlik ve güvenirlik çalışmaları vardır (Atroshi, Gummesson, Andersson, Dahlgren, \& Johansson, 2000; Fayad et al., 2008; Finsen, 2008; Hervás et al., 2006; E. Lee, Chung, Li, \& Lo, 2005; J.-Y. Lee, Lim, Oh, \& Ko, 2008; Themistocleous et al., 2006). Ayrlca romatoid artrit, distal radius kırıkları, psoriatik artrit gibi hastalıklara ve sanayi çalışanlarına özgü geçerlik ve güvenirlik çalışmaları da yapımıştır (Kitis, Celik, Aslan, \& Zencir, 2009; Navsarikar, Gladman, Husted, \& Cook, 1999; Raven et al., 2008; Westphal, Piatek, Schubert, Schuschke, \& Winckler, 2001). Ülkemizde ise DASH anketinin Türkçe versiyonunun (DASH-T) geçerlik ve güvenirliği Düger ve arkadaşları tarafından 2006 yılında yapılmıştır (Düger et al., 2006). DASH-T anketi birey tarafından doldurulur ve 3 bölümden oluşur: Fonksiyonel/semptom (DASH-FS), iş modeli (DASH-W) ve sporlar-müzisyenler modeIi (DASH-SM). İş modeli ve sporlar-müzisyenler modeli isteğe bağlı olarak doldurulur. ilık bölüm 30 sorudur. Bu 30 sorudan 21'i kişinin günlük yaşam aktiviteleri sırasındaki zorlanmalarını, 5'i semptomlarını (ağrı, sertlik, karıncalanma, güçsüzlük) ve 4'ü ise iş, uyku, sosyal fonksiyon ve kendine güveni değerlendirir. İş modeli hastanın çalışma yaşamındaki özrünü gösterir ve 4 sorudan oluşur. Sporlar-müzisyenler modeli ise spor yapan ya da müzisyen olan bireylerin özrünü gösterir ve 4 sorudan oluşur. Kişi bütün sorulara 5'li likert sistemine göre yanıt verir (1: zorluk yok, 2: hafif derecede zorluk, 3: orta derecede zorluk, 4: aşırı zorluk, 5: hiç yapamama). Her bölümden 0-100 arasında bir puan elde edilir. Puan arttıkça özür de artar (Düger ve diğ., 2006). Çalışmamızda DASH-T anketinin ilk 30 sorusu uygulanmıştır.

Lawton Günlük Yaşam Aktiviteleri (LGYA) Anketi, bireylerin günlük yaşam aktivitelerini değerlendiren en eski testlerden biridir (Kayıhan $\mathrm{H}$., 2002). Test; Yatak, Tekerlekli Sandalye, Kendine Bakım, Yemek Yeme ve Giyinme Aktivitelerinden oluşur (Lawton, 1963). Test değerlendirilirken bağımsız, gözlem gerekiyor, yardımla yapıyor ve tamamen bağımlı şeklinde yorumlanır (Kayıhan, 1982). Çalışmamızda LGYA Anketinin kendine bakım, yemek yeme ve giyinme aktiviteleri değerlendirilmiştir ve bu aktiviteler değerlendirilirken yazarlar tarafından bağımsız 4 puan, gözlem 
gerekiyor 3 puan, yardımla yapıyor 2 puan ve tamamen bağımlı ise 1 puan şeklinde puanlanmıştır. Puan arttıkça bireyin bağımsızlık düzeyi de artmaktadır. LGYA anketinin bu 3 parametresi (kendine bakım, yemek yeme ve giyinme aktiviteleri) toplamda 0-84 arasında puanlanmıştır. Kendine bakım aktiviteleri 0-32 puan, yemek yeme aktiviteleri 0-24 puan ve giyinme aktiviteleri ise $0-28$ puan arasındadır.

\section{İstatistiksel Analiz}

Araştırma verilerinin istatistiksel analizlerinde SPSS 21 istatistik programı kullanıldı. Değişkenlerin tanımlayıcı istatistikleri ortalama, standart sapma, minimum ve maksimum olarak hesaplandı. Değişkenlerin normal dağılıma uygunluğu görsel (histogram ve olasılık grafikleri) ve analitik yöntemlerle (Kolmogorov-Smirnov testi) incelendi. Bunun sonucunda normal dağılım göstermeyen DASH-T Anketi ve LGYA Anketi sonuçları arasındaki ilişkiyi belirlemek için nonparametrik korelasyon analiz yöntemi olan Spearman testi yapıldı. Testler \%5 anlamlılık seviyesinde gerçekleştirildi. Korelasyonun derecelendirmesi; korelasyon katsayısı 0,05-0,30 düşük, 0,30-0,40 düşük-orta, 0,40-0,60 orta derece, 0,60-0,70 iyi derece, 0,70-0,75 çok iyi derece ve 0,75-1,00 mükemmel korelasyon olarak tanımlanmıştır (M. Hayran, 2011).

\section{SONUÇLAR}

Çalışmaya alınan 52 bireyden \% 67'si kadın $(n=35), \% 32$ 'si erkektir ( $n=17)$. Çalışmaya katılan bireylerin yaş ortalaması $45,81 \pm 15,42$ yıldır. Bireylerin \% 50'si ( $n=26)$ cerrahi operasyon geçirmiştir. Bireylerin \% 50'si $(n=26)$ kırık, \% 23'ü sinir yaralanması $(n=12), \% 15^{\prime} i(n=8)$ tendon yaralanması ve \% 12'si $(n=6)$ yumuşak doku yaralanması tanısına sahiptir.

DASH-T anketinin günlük yaşam aktivitelerini içeren ilk 21 maddesi ile LGYA anketindeki aktiviteler karşılaştırılmış ve DASH-T anketindeki 21 aktiviteden sadece dördünün LGYA anketinde bulunduğu sonucuna ulaşımıştır (Tablo 1). Bu maddelerden ikisi kendine bakım, biri giyinme ve biri de yemek yeme aktivitelerinin alt maddeleridir. Bu maddeler; saçları yıkamak veya kurulamak, sırtını yıkamak, kazak giymek, yiyecekleri kesmek için bıçak kullanmaktır. DASH-T anketindeki 21 akti- viteden 16' sı yardımcı GYA ve 5' i temel GYA' dır. DASH-T anketinde bulunan temel GYA' lar; saçları yıkamak veya kurulamak, sırtını yıkamak, kazak giymek, yiyecekleri kesmek için bıçak kullanmak ve cinsel faaliyetlerdir. LGYA anketindeki aktivitelerin tamamı temel GYA' dır ("Occupational Therapy Practice Framework: Domain and Process," 2014).

Kişilerin DASH-T ve LGYA Anketi sonuçlarının ortalaması, minimum ve maksimum değerleri Tablo 2'te gösterilmiştir. Her iki anketin ortalama puanlarına bakıldığında; DASH-T anketi sonucu bireyler ortalama 38,92 $\pm 25,28$ puan almışken, bireylerin Lawton kendine bakım aktivitelerinde ortalama 25,49 $\pm 4,2$, yemek yeme aktivitelerinde $21,92 \pm 3,7$ ve giyinme aktivitelerinde $26,43 \pm$ 4,3 puan aldıkları görülmüştür.

DASH-T ile LGYA arasında istatistiksel olarak orta düzeyde ilişki bulunmuştur $(r=-0,571$, $\mathrm{p}<0,01)$. DASH-T, Lawton kendine bakım aktiviteleri $(r=-0,572, p<0,01)$ ve giyinme aktiviteleriyle $(r=-0,579, p<0,01)$ negatif yönde, orta düzeyde bir korelasyona sahip iken, Lawton yemek yeme aktiviteleriyle $(r=-0,394, p<0,05)$ negatif yönde, düşük-orta düzeyde bir korelasyona sahiptir.

\section{TARTIȘMA}

Klinikte sıklıkla kullanılan DASH-T ve LGYA anketlerini temel olarak ele aldığımız çalışmamızda DASH-T ve LGYA kendine bakım, yemek yeme ve giyinme parametreleri arasında orta düzeyde bir ilişki olması ve her iki anket arasında sadece ortak dört aktivite olması sonucu, DASH-T anketinin üst ekstremite yaralanması geçirmiş bireylerin günlük yaşam aktivitelerindeki her parametreyi değerlendirmediği ve LGYA anketinin bu bireylerin aktivite limitasyonlarını belirlemede yetersiz olabileceğini düşünmekteyiz.

DASH-T anketi ile Lawton kendine bakım, giyinme ve yemek yeme aktiviteleri arasındaki ilişkiye baktığımızda; LGYA' da kendine bakım aktivitelerinde 8 parametre, giyinme aktivitelerinde 7 parametre ve yemek yeme aktivitelerinde $6 \mathrm{pa}$ rametre bulunmaktadır. DASH-T anketinin, LGYA kendine bakım aktiviteleriyle ortak iki maddesi (saçları yıkamak veya kurulamak, sırtını yıkamak), LGYA giyinme aktiviteleriyle ortak bir maddesi (kazak giymek) ve LGYA yemek yeme aktiviteleriyle ortak bir maddesi (yiyecekleri kesmek için 
Tablo 1: DASH-T Anketi ile LGYA anketinin karşılaştırılması

\begin{tabular}{|c|c|}
\hline DASH-T Aktiviteler & LGYA \\
\hline 1-Sıkı kapatılmış ya da yeni bir kavanozu açmak & - \\
\hline 2-Yazı yazmak & - \\
\hline 3-Anahtarı çevirmek & - \\
\hline 4-Yemek hazırlamak & - \\
\hline 5-Zor açılan bir kapıyı iterek açma & - \\
\hline 6-Yukarıdaki bir rafa bir şey yerleştirmek & - \\
\hline $\begin{array}{l}\text { 7-Ağır ev işleri yapmak } \\
\text { (duvar silmek, yer silmek, tamirat yapmak vs.) }\end{array}$ & - \\
\hline 8-Bağ bahçe işleri yapmak, odun kesmek & - \\
\hline 9-Yatak yapmak & - \\
\hline 10-Alışveriş çantası ya da evrak çantası taşımak & - \\
\hline 11-Ağır bir cismi taşımak (4.5 kg'dan fazla) & - \\
\hline 12-Yukarıdaki bir ampulü değiştirmek & - \\
\hline 13-Saçları yıkamak veya kurulamak & + (Gövde ve ekstremite yıkama) \\
\hline 14-Sırtını yıkamak & + (Gövde ve ekstremite yıkama) \\
\hline 15-Kazak giymek & + (Kazak, süeter giymek) \\
\hline 16-Yiyecekleri kesmek için bıçak kullanmak & + (Bıçak kullanma) \\
\hline $\begin{array}{l}\text { 17-Az çaba gerektiren eğlendirici işler } \\
\text { (iskambil oynamak, örgü örmek vs.) }\end{array}$ & - \\
\hline $\begin{array}{l}\text { 18-Kolunuzdan, omzunuzdan veya elinizden güç aldığınız veya darbe } \\
\text { vurduğunuz eğlenceye yönelik etkinlikler (önünüzde yerde bulunan } \\
\text { bir konserve kutusu veya küçük bir taşa iki elinizle kavradığınız bir } \\
\text { sopayla yandan vurmak, tenis oynamak, pinpon oynamak) }\end{array}$ & - \\
\hline $\begin{array}{l}\text { 19-Kolunuzu serbestçe hareket ettirdiğiniz eğlendirici işler (suda taş } \\
\text { kaydırmak, meyve taşlama, çelik çomak oynama) }\end{array}$ & - \\
\hline $\begin{array}{c}\text { 20-Ulaşım ihtiyaçlarını kendi başına giderebilmek (bir yerden başka } \\
\text { bir yere gitmek) }\end{array}$ & - \\
\hline 21-Cinsel faaliyetler & - \\
\hline
\end{tabular}

DASH-T ve LGYA anketinde ortak olarak bulunan aktiviteler (+) ile, ortak olmayan aktiviteler (-) ile gösterilmiştir.

Tablo 2: DASH-T ve LGYA Sonuçları

\begin{tabular}{|c|c|c|c|}
\hline & Ortalama \pm SS & Minimum & Maksimum \\
\hline DASH-T & $38,92 \pm 25,28$ & 0,83 & 93,10 \\
\hline $\begin{array}{c}\text { Lawton Kendine Bakım } \\
\text { Aktiviteleri }\end{array}$ & $25,49 \pm 4,2$ & 9 & 28 \\
\hline $\begin{array}{c}\text { Lawton Yemek Yeme } \\
\text { Aktiviteleri }\end{array}$ & $21,92 \pm 3,7$ & 6 & 24 \\
\hline Lawton Giyinme Aktiviteleri & $26,43 \pm 4,3$ & 7 & 28 \\
\hline
\end{tabular}


bıçak kullanmak) vardır. Ortak madde sayısı kendine bakım, giyinme aktiviteleri ve yemek yeme aktiviteleri için az olmasına rağmen iki anket arasında orta düzeyde korelasyon bulunmasının sebebi, DASH-T anketinde bireylere uygulanan 30 sorudan 5'inin semptomları (ağrı, sertlik, karıncalanma, güçsüzlük) değerlendirmesi olabilir. Çünkü hastalığın semptomları bireylerin ağır cisimleri taşıma, yazı yazma gibi GYA' larını etkilemektedir (Zhang et al., 2002). Dolayısıyla DASH-T anketi ve LGYA' nın kendine bakım, giyinme ve yemek yeme aktiviteleri arasındaki bu orta düzeyde korelasyonun daha çok semptom puanlarının etkisini yansıttığı nedeniyle gerçek bir sonuç vermediğini düşünmekteyiz.

Korelasyon analizi sonuçları genel olarak incelendiğinde DASH-T ve LGYA arasında orta düzeyde ilişki çıkmasının sebeplerinden biri de DASH-T anketindeki aktivitelerin yüksek oranda yardımcı GYA' Iardan oluşması ve LGYA anketindeki aktivitelerin ise zit olarak temel GYA' lardan oluşması olabilir. DASH-T anketinde bulunan 5 temel GYA' dan dördü LGYA anketinde bulunan aktivitelerdir. Sonuç olarak DASH-T anketindeki temel GYA' lar büyük oranda LGYA anketinde bulunsa da, DASH-T anketi LGYA anketinde bulunan el-yüz yıkama, diş fırçalama, bardak fincan kullanma, pantolon giyme gibi diğer temel GYA' ları değerlendirmede yetersiz kalmaktadır. LGYA anketi de yardımcı GYA' ları değerlendirmede yetersizdir. Literatürde belirtildiği üzere üst ekstremite yaralanmalarında daha çok yardımcı GYA' lar etkilenmektedir. Bundan dolayı DASH-T anketi üst ekstremite yaralanması geçirmiş bireylerin yardımcı GYA' daki zorlanmalarını daha iyi ortaya koyabilmektedir, ancak yine de bireylerin zorlandıkları bütün GYA' ları tam olarak yansıtamamaktadır.

DASH-T anketi, bağımsızlıktan ziyade bireylerin özrünü göstermekte ve üst ekstremite yaralanması geçirmiş bireylerin günlük yaşamdaki bağımsızı̆̆ına yönelik tedavi programı oluşturmada ve aktiviteleri ayrıntılı olarak analiz etmede yeterli olamamaktadır. Bundan dolayı üst ekstremite yaralanması geçirmiş bireylerin günlük yaşamdaki bağımsızlıklarını ayrıntıı olarak değerlendirmek için klinikte DASH-T anketinin yanında özellikle temel GYA' ları değerlendiren ayrıntılı bir GYA değerlendirmesi yapılması önemlidir. Bu bireyle- rin rehabilitasyonunda günlük yaşamdaki bağımsızlıklarına yönelik yapılacak müdahaleler için bu değerlendirmelerin önemli olduğunu düşünmekteyiz.

Çalışmamızın kısıtlılıkları, sonuçları değerlendirirken göz önünde bulundurulmalıdır. Çalışmaya daha fazla birey dahil edilmesi DASH ve LGYA arasındaki ilişkiyi daha net ortaya koyabilir. Çalışma, DASH-T ve LGYA arasındaki ilişkiyi ortaya koymayı amaçlasa da, klinikte sıklıkla kullandığımız LGYA anketinin üst ekstremite yaralanması geçirmiş bireylerde geçerli ve güvenilir bir anket olmaması sebebiyle alt parametrelerinin bu bireylerin etkilenmiş GYA' larını ortaya koyması açısından yetersiz kalmış olabileceğini düşünmekteyiz. Ayrıca içerisinde daha çok temel günlük yaşam aktiviteleri bulunan LGYA anketi yerine hem temel hem de yardımcı günlük yaşam aktivitelerini içeren ölçeklerin kullanılmasının, DASH gibi el ölçüm anketleri ve GYA arasındaki ilişkiyi belirlemede daha iyi olacağı görüşündeyiz. İleriki çalışmalar için, GYA ve el ölçüm anketleri arasındaki ilişkiyi değerlendirmede üst ekstremite yaralanmalarındaki belli tanı gruplarına yönelik daha spesifik araştırmalar yapılmasını ve LGYA anketine yönelik uzman görüşü alınması gerektiğini önermekteyiz.

\section{SONUÇ}

Günümüzde üst ekstremite yaralanması geçirmiş bireylerde GYA değerlendirmesinden çok özrün ölçülmesi ön planda olsa da, bu bireylerde GYA' lar etkilenmektedir. Ancak bu bireylere yönelik spesifik ve ayrıntılı bir GYA değerlendirmesi yoktur. Çünkü mevcut GYA değerlendirmeleri daha çok mobilite ve kognitif duruma odaklanmaktadır. Her ne kadar üst ekstremite yaralanmalarında bireyler bu parametreler açısından da zorluk yaşasalar da, daha çok üst ekstremitenin fonksiyonel olarak kullanıldığı aktivitelere odaklanan GYA değerlendirmelerinin önemi kaçınılmazdır. Bu bireylerde kullanılacak GYA değerlendirmelerinin yardımcı GYA' ları içermesi, anketin standardize, geçerlik ve güvenirliğinin çalışmalarla analiz edilmiş olması ve puanlama sisteminin bireylerin aktivitelerindeki bağımsızlık düzeylerini yansıtacak şekilde olması önemlidir. 


\section{KAYNAKLAR}

Atroshi, I., Gummesson, C., Andersson, B., Dahlgren, E., \& Johansson, A. (2000). The disabilities of the arm, shoulder and hand (DASH) outcome questionnaire: Reliability and validity of the Swedish version evaluated in 176 patients. Acta Orthopaedica Scandinavica, 71(6), 613-618. doi:10.1080/000164700317362262

Changulani, M., Okonkwo, U., Keswani, T., \& Kalairajah, Y. (2008). Outcome evaluation measures for wrist and hand - which one to choose? International Orthopaedics, 32(1), 1-6. doi:10.1007/s00264007-0368-z

Davis, A. M., Beaton, D., Hudak, P., Amadio, P., Bombardier, C., Cole, D., ... Marx, R. (1999). Measuring disability of the upper extremity: a rationale supporting the use of a regional outcome measure. Journal of Hand Therapy, 12(4), 269-274.

Düger, T., Yakut, E., Öksüz, Ç., Yörükan, S., Bilgütay, B., \& Ayhan, Ç. (2006). Kol, omuz ve el sorunları (disabilities of the arm, shoulder and hand-DASH) anketi Türkçe uyarlamasının güvenirliği ve geçerliği. Fizyoter Rehabil, 17(3), 99-107.

Fayad, F., Lefevre-Colau, M.-M., Macé, Y., Fermanian, J., Mayoux-Benhamou, A., Roren, A.,... Revel, M. (2008). Validation of the French version of the Disability of the Arm, Shoulder and Hand questionnaire (F-DASH). Joint Bone Spine, 75(2), 195-200.

Finsen, V. (2008). Norwegian version of the DASH questionnaire for examination of the arm shoulders and hand. Tidsskrift for den Norske lægeforening: tidsskrift for praktisk medicin, ny række, 128(9), 1070.

Hervás, M., Navarro, C. M., Peiró, S., Rodrigo, P. J., López, M. P., \& Martínez, T. I. (2006). [Spanish version of the DASH questionnaire. Cross-cultural adaptation, reliability, validity and responsiveness]. Medicina clínica, 127(12), 441-447.

Kayıhan, H. (1982). Hemiplejik hastaların günlük yaşam aktiviteleri eğitiminde bağımsızlık kazanmalarına değişik faktörleri etkileri üzerinde karşılaştırmalı bir çalışma. Hacettepe Üniversitesi.

Kayıhan H., U. M., Armutlu K., Soyuer F., Düger T., Bumin G. (2002). Multiple Sklerozlu Hastalarda Dört, Günlük Yaşam Aktivitesi Testinin Karşılaştırılması. Erciyes Üniversitesi Sağlık Bilimleri Dergisi, 11, 8-14.

Kitis, A., Celik, E., Aslan, U. B., \& Zencir, M. (2009). DASH questionnaire for the analysis of musculoskeletal symptoms in industry workers: a validity and reliability study. Applied Ergonomics, 40(2), 251-255.

Lawton, B. (1963). Activities of daily living for physical rehabilitation: McGraw-Hill Company.

Lee, E., Chung, M., Li, A., \& Lo, S. (2005). Construct validity of the Chinese version of the disabilities of the arm, shoulder and hand questionnaire (DASH-HKPWH). The Journal of Hand Surgery: British \& European Volume, 30(1), 29-34.

Lee, J.-Y., Lim, J.-Y., Oh, J. H., \& Ko, Y.-M. (2008). Cross-cultural adaptation and clinical evaluation of a Korean version of the disabilities of arm, shoulder, and hand outcome questionnaire (K-DASH). Journal of Shoulder and Elbow Surgery, 17(4), 570-574. doi: http://dx.doi.org/10.1016/j.jse.2007.12.005

Navsarikar, A., Gladman, D., Husted, J., \& Cook, R. (1999). Validity assessment of the disabilities of arm, shoulder, and hand questionnaire (DASH) for patients with psoriatic arthritis. The Journal of Rheumatology, 26(10), 2191-2194.

Occupational Therapy Practice Framework: Domain and Process. (2014). The American Journal of Occupational Therapy, 68, 1-48.

Raven, E. E., Haverkamp, D., Sierevelt, I. N., van MONTFOORT, D. O., PÖLL, R. G., Blankevoort, L., \& Tak, P. P. (2008). Construct Validity and Reliability of the Disability ofArm, Shoulder and Hand Questionnaire for Upper Extremity Complaints in Rheumatoid Arthritis. The Journal of Rheumatology, 35(12), 2334-2338.

Schoneveld, K., Wittink, H., \& Takken, T. (2009). Clinimetric evaluation of measurement tools used in hand therapy to assess activity and participation. Journal of Hand Therapy, 22(3), 221-236.

Skirven, T. M., Osterman, A. L., Fedorczyk, J., \& Amadio, P. C. (2011). Rehabilitation of the Hand and Upper Extremity, 2-Volume Set: Expert Consult: Elsevier Health Sciences.

Themistocleous, G. S., Goudelis, G., Kyrou, I., Chloros, G. D., Krokos, A., Galanos, A., ... Soucacos, P. N. (2006). Translation into Greek, Cross-cultural Adaptation and Validation of the Disabilities of the Arm, Shoulder, and Hand Questionnaire (DASH). Journal of Hand Therapy, 19(3), 350-357. doi: http://dx.doi.org/10.1197/j. jht.2006.04.014

Tuncalı D., T. K., Terzioğlu A., Aslan G. (2005). Üst Ekstremite Akut Tendon Yaralanmaları: Epidemiyolojik Değerlendirme. Türk Plastik Rekonstrüktif ve Estetik Cerrahi Dergisi, 13(2), 114-118.

van de Ven-Stevens, L. A., Munneke, M., Terwee, C. B., Spauwen, P. H., \& van der Linde, H. (2009). Clinimetric properties of instruments to assess activities in patients with hand injury: a systematic review of the literature. Archives of Physical Medicine and Rehabilitation, 90(1), 151-169.

Westphal, T., Piatek, S., Schubert, S., Schuschke, T., \& Winckler, S. (2001). [Reliability and validity of the upper limb DASH questionnaire in patients with distal 
radius fractures]. Zeitschrift fur Orthopadie und ihre Grenzgebiete, 140(4), 447-451.

Zhang, Y., Niu, J., Kelly-Hayes, M., Chaisson, C. E., Aliabadi, P., \& Felson, D. T. (2002). Prevalence of Symptomatic Hand Osteoarthritis and its impact on Functional Status among the ElderlyThe Framingham Study. American Journal of Epidemiology, 156(11), 10211027. doi:10.1093/aje/kwf141 